\title{
Lyophilized Powder for Injectable Solution Dosage Form
}

National Cancer Institute

\section{Source}

National Cancer Institute. Lyophilized Powder for Injectable Solution Dosage Form. NCI

Thesaurus. Code C42957.

A freeze dried powder intended for injection following reconstitution with a suitable solvent to form a solution. 